\title{
The effectiveness of humanitarian supply chain management in Zimbabwe
}

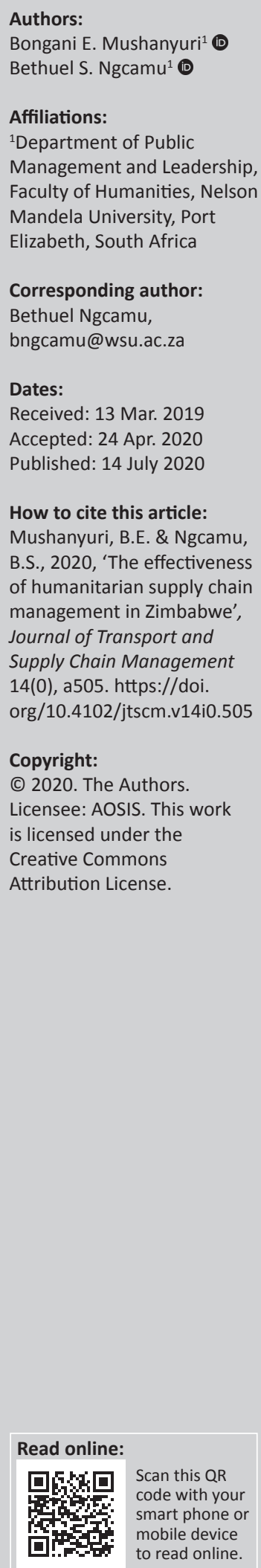

Background: Supply chain management (SCM) implementation in selected drought-stricken areas in Zimbabwe has been negatively influenced by the marginalisation of indigenous leaders and an intolerant political system.

Objectives: This study examines the influence of culture and leadership attitudes, as well as the political, economic and legal framework, on the effectiveness of the humanitarian supply chain (HSC) during droughts in Zimbabwe. The effect of culture, leadership attitudes, and the political, economic and legal framework on HSC effectiveness in Zimbabwe has not been explored by researchers.

Method: The study adopted a quantitative exploratory research design utilising the case study approach. The study sample consisted of 130 respondents comprising government and non-governmental organisation (NGO) officials whose primary responsibilities are drought disaster operations.

Results: The study results revealed that the culture, leadership attitudes and political state did not positively influence the effectiveness of the HSC in Zimbabwe. In addition, the economic state and legal framework positively influenced the effectiveness of the HSC on drought management. Accordingly, the empirical results found that the existing legal framework positively influenced the effectiveness of the HSC. Furthermore, an association between educational background and work experience had an impact on the reduction of transport and warehouse costs, which are critical components of a humanitarian relief supply chain.

Conclusion: This study is expected to significantly contribute to the crafting of effective HSC and intervention strategies. The study also adds to the body of knowledge in HSC and disaster management as there is a shortage of empirical data in this field of study.

Keywords: drought; disaster management; supply chain management; humanitarian supply chains; drought relief supply chains.

\section{Introduction}

Effective disaster responses in developing countries such as Zimbabwe have been credited to efforts from a myriad of stakeholders, including traditional leadership (chiefs), non-governmental organisations (NGOs) and government agencies. Previous stakeholders which play a significant role in food allocation and distribution during and in the aftermath of a disaster seem to be ignored and neglected by government agencies. In this epoch of political instability in Zimbabwe, chiefs are considered credible by the international community in the form of NGOs that provide aid to the indigent. The country's isolation from the international community has compounded the country's inability to respond effectively to drought disasters. While drought is seen as a primary cause of food shortages in the country, sections of the society believe that the manner in which the land was redistributed exacerbated the problem. This has led to strained relations with countries with developed economies and multi-lateral institutions which has adversely affected the response of the humanitarian supply chain (HSC) to drought. Drought as a natural catastrophe has caused disruptions and the negative performance of members of supply chain management (SCM) (Hosseini, Ivanov \& Dolgui 2019; Xu et al. 2020:1). Zimbabwe has experienced floods and droughts, and the impacts of the tropical cyclones have been exacerbated by economic and political risks (Chari \& Ngcamu 2019a:3, 2019b:7). Zimbabwe was struck by Cyclone Idai in March 2019, which left 344 dead, 270000 displaced and others missing (Devi 2019:1585). The Chimanimani and Chipinge Districts were hardest hit, and agriculture, schools and infrastructure all suffered substantially.

Tadesse (2016:14) defines drought response as 'efforts such as the provision of assistance or intervention during or immediately after a drought disaster to meet the life preservation and 
basic subsistence needs of those people affected'. Da Costa, Campos and De Mello Bandeira (2012) argue that disaster response is a stage of disaster management which attracts diverse stakeholders or role players. To save lives and minimise damage, when disaster events strike, individuals, communities, humanitarian organisations and countries work together to assist affected communities (Coppola 2011). The task of limiting injuries, loss of life and damage to property and the environment form the core of emergency response (Van Wassenhove 2006). The response includes activities that directly address needs, such as first aid, search and rescue, and shelter (Coppola 2011; Cozzolino 2012).

The present study explores the influence of culture, leadership attitudes, and the political, economic and legal framework on the effectiveness of the HSC in Zimbabwe against the background of the need for basic aid currently prevailing in the country. Some researchers have focussed their research studies by assessing the effects of dairy companies with government and NGOs in reducing disaster risks (Chari \& Ngcamu 2017b), and the performance of dairy supply risks being affected by disaster risks (Chari \& Ngcamu 2017a) in Zimbabwe. Other studies have either interrogated the impact of disaster risks on the economics of the seed cotton supply chain (Chari \& Ngcamu 2019a) or focussed on the victims of Cyclone Dineo (Mhlanga, Musingili \& Mpambela 2019). Accordingly, Xu et al. (2020:1) posit that the field of supply chain disruption has been a focal and crucial point on mitigating the risks and improving the supply chain performance. During and in the aftermath of the Cyclone Idai, response strategies were innovative, and good practice was demonstrated as the first responders were local people, companies and councils (Chatiza 2019). The author posits that the agricultural sector has also been underperforming, which is primarily attributed to poor government policies, and droughts. Numerous researchers (Anseeuw et al. 2012:46; Mzumara 2012:41) argue that the political instability in Zimbabwe was influenced by the land reform programme, which commenced in 2000. Recently published empirical studies (Chari \& Ngcamu 2019a, 2019b, 2017a, 2017b) reveal a void in the literature as there are no research studies that have explored the influence of culture, leadership attitudes, and the political, economic and legal framework. Furthermore, there is a paucity of data dissecting the effectiveness of HSCs in developing countries such as Zimbabwe. This gap in the literature has necessitated a distinct need of the research study:

- To explore the role of the HSC in response to drought in light of culture, leadership attitudes, the political and economic state, and the legal framework.

- To assess current HSC's strategies being applied by the government and NGOs in selected drought-prone areas of Zimbabwe.

\section{Literature review}

This section is detailed synthesised literature on drought and the effectiveness and loopholes on the HSC in developing countries, and Zimbabwe is no exception.

\section{Drought status and its effect in Zimbabwe}

The history of world disasters is well-documented, and its forecasts suggest that such occurrences will increase in intensity and frequency. The anticipated increase in disaster activity in the world has attracted immense interest from researchers (e.g. Balcik et al. 2010; Da Costa et al. 2012; Oloruntoba \& Gray 2006; Tomasini \& Van Wassenhove 2009; Van Wassenhove 2006). These authors primarily focussed on the role of SCM in disaster preparedness and response. The majority of available strands of literature have mainly been on sudden-onset disasters such as the Indian Ocean earthquake in 2004, Hurricane Katrina in 2005, the Pakistan earthquake in 2005, the Yogyakarta earthquake in 2006, the Haiti earthquake in 2010, the Japan earthquake in 2011, and the Brazil flooding and landslides in 2011. However, droughts and disease epidemics that have equally devastating consequences have not received as much attention from researchers (Tadesse 2016).

In addition to the effects of political instability and natural disasters such as Cyclone Idai, Zimbabwe is prone to frequent droughts. The World Food Programme (WFP 2016) reported that Zimbabwe would experience frequent drought disasters in the future (Emergency Events Database [EM-DAT] 2014). However, drought is prevalent in regions IV and $\mathrm{V}$, considered to be semi-arid agro-ecological, and incidences of drought are experienced throughout the country due to seasonal shifts and increased dryness (Mararike 2001:53-65; Masendeke \& Shoko 2014). The Zimbabwe Vulnerability Committee (ZIMVAC) (ReliefWeb 2016) reported that over three million people in areas such as Chiredzi, Bikita, Chivi, Chipinge, Binga, Buhera, Tsholotsho, Kariba, Mwenezi, Bulilima, Mangwe and Hwange needed food relief. The Zimbabwe Vulnerability Committee (ReliefWeb 2016) further projected the number of people in need of drought relief to increase to 4.1 million by 2020. The Zimbabwe Human Rights Commission (ZHRC) also pointed out that food was being distributed along factional lines, resulting in some deserving families and individuals being deprived of food aid because of their political affiliation (ZHRC 2016). The politicisation of food relief, especially in rural communities, was also widely reported by local and international election observers (the Southern African Community Development, the African Union and the European Union, amongst others) during the 2018 national harmonised elections, when food relief was used by political players to canvas for votes. The background provided above triggered this study to establish the impact of culture, leadership attitudes, and the political state, economic state and legal framework on the effectiveness of drought supply chains in Zimbabwe.

\section{Disaster and humanitarian response}

The different role players come with divergent expectations, equipment and mission, which sometimes create discord amongst them (Cozzolino 2012). The presence of diverse role players during the response stage brings to the fore coordination complexities in disaster response initiatives. 
The discord amongst the different role players impedes the effectiveness of HSCs (Balcik et al. 2010). The HSC relief operation under the auspices of HSC functions under a blend of various activities including the collaboration and coordination of humanitarian relief, communication and aid, the aim of which is to effectively and efficiently ensure victims' safety (Agarwal \& Singh 2018:99). The success of disaster response depends heavily on the information available and the coordination of activities by diverse role players (Balcik et al. 2010). Coordination in disaster response is further complicated by the fact that each disaster event is unique in terms of the participants, needs of the victims and the communities (Balcik et al. 2010). According to Chatiza (2019), the lessons learnt during Cyclone Idai for future responses should include general public empathy and mobilisation, and immunisations against cholera and measles. The author further argues that for disaster response to be proactive, emergency responses from the private sector, reassignments of the national budget, communication on responses and funding should be made transparent by government. In addition, psychosocial support should be mainstreamed, and the social protection of children as well as numerous service innovations should be made available.

\section{Supply chain management performance metrics}

The majority of researchers (Da Costa et al. 2012; Mohan et al. 2011; Patemen et al. 2013) concur that SCM is at the core of a successful disaster management operation. The measure of supply chain performance is an aspect which has drawn the attention of many researchers (Beamon \& Balcik 2008). According to Beamon and Balcik (2008:13), the humanitarian sector has not developed the performance metrics and measurement systems, while NGOs are aware of the significance of such tools because they compete for scarce resources and accountability demands from donors. The authors further posit that NGOs measure performance that focusses on input metrics (including financials and non-financials) rather than outputs, whereas Kara and Rancourt (2019) cite the HSC performance metrics as cost, distance and/or time.

The transportation of relief aid is regarded as a determinant of an effective drought relief operation (Tomasini \& Van Wassenhove 2009). The most used modes of transport in disaster response are road, sea, air and railway (Da Costa et al. 2012). During disasters, most organisations face difficulties transporting goods, including clothing, food, medicine and medical supplies, as well as moving machinery from different points of origin to their destinations (Agarwal \& Singh 2018:99). Beamon and Balcik (2008) identified three major disaster response performance metrics, namely, resource performance metrics, output performance metrics and flexibility.

\section{Cultural factors}

Wisner et al. (2004) consider culture to affect response actions to disasters. Zimbabwe's traditions, culture and traditional leaders (such as chiefs) have important roles in society (Masendeke \& Shoko 2014). These authors argue that the administrative role of chiefs is still being recognised in the country - for example, they maintain peace and order in their areas of jurisdiction. According to Wisner et al. (2004), cultural factors are often ignored during the planning and implementation of disaster risk reduction (DRR) strategies. Nunn et al. (2007) also point out that a failure to deal with cultural factors often resulted in communities being more vulnerable to disaster events and the failure of DRR strategies. Meanwhile, there is an increasing demand for HSC management in the event of the specialisation of stakeholders due to cultural, political, geographical and historical differences (Agarwal \& Singh 2018:100).

\section{Economics and political factors}

The Zimbabwean economy has been on a downward trajectory for a very long time. Since 2013, real gross domestic product (GDP) growth has decelerated by an estimated $9 \%$ (Zimbabwe Reserve Bank report 2016). Impoverished communities are inherently exposed to diseases and starvation, and they rely on relief organisations such as NGOs for daily survival (Khan et al. 2008). The Zimbabwean political system has been considered to be intolerant towards NGOs and has restricted its operations (Bongo et al. 2013; Collier 2008:68) by exercising political and economic control and power (Agarwal \& Singh 2018:100). The little aid available is distributed along political lines (ZHRC 2016). Muchanyerei (2017) also observed that the Zimbabwean political discourse had caused apathy and fear amongst food aid providers. Tomasini and Van Wassenhove (2009:10) also point to how HSCs are heavily politicised. Governments may reject aid from donors who are presumed to harbour hidden agendas.

\section{Leadership attitudes}

According to Chigwedere et al. (2008), leadership attitudes can positively or negatively influence DRR. Chari and Ngcamu (2019b) believe that a myriad of leaders from the private sector, NGOs and government agencies play a crucial part in DRR. Whereas the adverse impact of supply chain members' performance has been credited to the disruptions in SCM (Xu et al. 2020), a shortage of studies associating leadership attitudes to drought and the effectiveness of relief supply chains has led to this study being conducted in selected areas in Zimbabwe.

\section{Legal framework}

The Civil Protection Act [Chapter 10:06] of 2001 is responsible for managing various types of disaster in Zimbabwe. The recurrence of droughts in the country necessitated the government to develop a National Policy on Drought Management (NPDM) dealing with drought contingency plans, including preparedness, mitigation and response. Furthermore, to regulate NGOs, the Private Voluntary Act [Chapter 17:05] of 2002 was developed. 


\section{Methodology}

This study focussed on response interventions to supply chains in the communities of Chiredzi, Bikita, Chivi, Chipinge, Binga, Buhera, Tsholotsho, Kariba, Mwenezi, Bulilima, Mangwe and Hwange. The districts under consideration are situated in ecological regions IV and V of Zimbabwe, which receive limited annual rainfall and are not suitable for crop farming (Masendeke \& Shoko 2014). Zimbabwe is divided into five ecological regions based on the amount of rainfall received, indicated in Figure 1.

\section{Research approach and strategy}

This research adopted an exploratory research design, exploring the role of supply chain interventions in drought disaster response. An exploratory approach was used because it utilises primary and secondary data-gathering techniques. The study employed quantitative research procedures in addressing the aims and research questions. Quantitative data were gathered through Likert-scaled questionnaires to examine the relationships between the variables of interest. A Cronbach's alpha test was used to test the reliability of the variable scales in the questionnaire. The results yielded a Cronbach's alpha coefficient of 0.856 and satisfied the minimum required reliability threshold at $\alpha \geq 0.7$ (Sekaran 2009). A single case study was used as this study focussed on Zimbabwe rather than on countries that are in the sub-Saharan region, which are also prone to drought. According to Quinlan et al. (2019), the major weakness of a case study approach is that it targets the study of a particular group, the selection of which is based on the unique characteristics of the group. A generalisation of results may not be possible for other groups due to differences in situations and characteristics. This study, however, was not weighed down by this weakness as it is the basis for selecting the case of Zimbabwe. In this regard, Zimbabwe was viewed

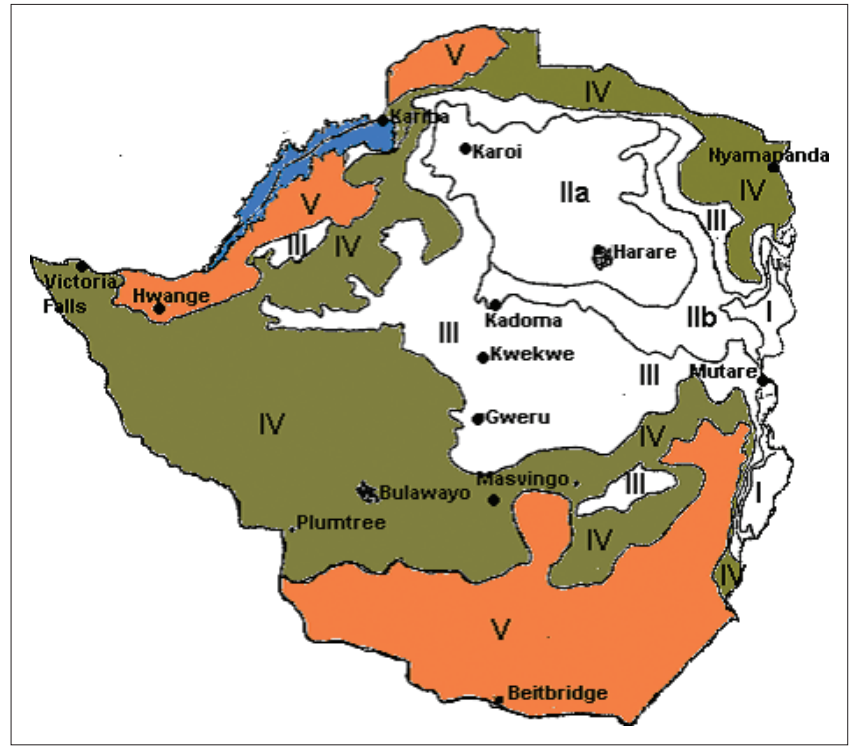

Source: Food and Agriculture Organization of the United Nations, n.d., Natural regions of Zimbabwe, viewed 23 January 2020, from http://www.fao.org/3/a0395e/a0395e06.htm

FIGURE 1: Map showing the five ecological regions in Zimbabwe. as unique and had a different drought disaster management environment to other sub-Saharan countries.

\section{Research sample}

The final sample $(n=130)$ comprised the categories shown in Table 1. The sample was drawn from the 12 districts of Chiredzi, Bikita, Chivi, Chipinge, Binga, Buhera, Tsholotsho, Kariba, Mwenezi, Bulilima, Mangwe and Hwange (ReliefWeb 2016).

\section{Measurement of key variables}

The independent regressors are termed enablers (culture, leadership attitudes, political state, economic state and legal framework). Supply chain effectiveness was proxied by transport costs, warehouse costs, quantity delivered and number of people affected by the drought relief supply chain, amongst others. Since the dependent variable is continuous and non-censored, the research objective can be estimated using ordinary least squares (OLS) (Cameroon \& Trivedi 2005; Wooldridge 2002) as follows:

$\mathrm{Y}_{i}=\alpha+$ Bnabler $_{i}+\mathrm{X}_{i}^{\prime} \gamma+\varepsilon_{i}$

[Eqn 1]

where $Y_{i}$ is the parameter supply chain effectiveness (transport cost, warehouse cost, quantity delivered or the number of people affected).

Enabler ${ }_{i}$ is the individual $i^{\prime}$ s proxy of supply chain enablers (culture, leadership attitudes, political state, economic state and policy framework) and $X_{i}$ is the vector of the background characteristics of the respondents and the organisations to which they belong.

In addition, to check robustness, a non-parametric test (called the sign test) was used to validate the results of the OLS procedure, which is the primary data analysis method (Anderson et al. 2008). In performing the sign test, an enabler

TABLE 1: Biographical data of the respondents.

\begin{tabular}{lcc}
\hline Variable & Frequency & Percentage \\
\hline Gender & 96 & 74 \\
Male & 34 & 26 \\
Female & 130 & 100 \\
Total & & \\
Age of respondents & 0 & 0 \\
18-24 & 66 & 51 \\
25-34 & 58 & 45 \\
35-44 & 5 & 4 \\
45-54 & 1 & 1 \\
55-64 & 0 & 0 \\
65 and above & 130 & 100 \\
Total & & \\
Education & 10 & 8 \\
O level & 9 & 7 \\
A level & 16 & 12 \\
Certificate & 71 & 55 \\
Diploma & 24 & 19 \\
Degree & 130 & 100 \\
Total & & \\
\hline
\end{tabular}

Note: Sample size $(n)=130$. 
influencing drought response was assigned 1 while 0 was assigned where an enabler was perceived to not influence the drought response. The authors also used heteroscedasticity robust standard errors.

\section{Data analysis and discussion of results}

The study's objective was to explore the role of SCM in drought disaster response in light of culture, leadership attitudes, political state, economic state and legal framework as enablers. The study also aimed to assess supply chain strategies currently being applied by the government and NGOs in response to drought relief. Notwithstanding this, the units of measurement were culture, leadership attitudes, political state of the country, economic state and legal framework, and their influence on drought relief supply chains in Zimbabwe, estimated using OLS.

As indicated in Table 1, male respondents constituted $74 \%$ of the sample, while $26 \%$ were female. Employment in the formal sectors in Zimbabwe is skewed towards males as reported in the United Nations-Zimbabwe report of 2016. At least $51 \%$ of the respondents were aged between 25 and 34 years, $45 \%$ were between 35 and 44 years, and 1\% was over 55 years of age. The qualifications of respondents varied from $\mathrm{O}$ levels being the minimum to university degrees being the maximum qualification. Table 1 also reveals that respondents with an $\mathrm{O}$ level education were $8 \%$, A level $7 \%$, certificate $12 \%$, diploma $55 \%$ and degree $19 \%$.

Table 2 is an illustration of the sample categories to which questionnaires were sent and their corresponding response rates. The response rates for each category were deemed satisfactory as they overwhelmingly exceeded the minimum threshold of $60 \%$ expected for external survey questionnaires

\begin{tabular}{lccc} 
TABLE 2: Response rate. & $\begin{array}{c}\text { Number of } \\
\text { questionnaires sent }\end{array}$ & $\begin{array}{c}\text { Number of } \\
\text { questionnaires received }\end{array}$ & $\begin{array}{c}\text { \% response } \\
\text { rate }\end{array}$ \\
\hline Government officers & 26 & 20 & 77 \\
NGO logistics officers & 35 & 29 & 83 \\
NGO projects officers & 13 & 13 & 100 \\
NGO field officers & 100 & 68 & 68 \\
\hline Total & $\mathbf{1 7 4}$ & $\mathbf{1 3 0}$ & $\mathbf{7 5}$ \\
\hline
\end{tabular}

NGO, non-governmental organisation.

\begin{tabular}{llcc}
\multicolumn{4}{l}{ TABLE 3: Sign test results on drought relief enablers. } \\
\hline Variable & Perception & Number (\%) & Z-stat \\
\hline Culture & Yes & 21 & 7.484 \\
& No & $79 \dagger$ & \\
Leadership attitudes & Yes & 21 & 7.484 \\
& No & $79 \dagger$ & \\
Political state & Yes & 20 & 7.016 \\
& No & $80 \dagger$ & \\
Economic state & Yes & $100 \dagger$ & 11.358 \\
& No & 0 & \\
Legal framework & Yes & $100 \dagger$ & 11.358 \\
& No & 0 & \\
\hline
\end{tabular}

Note: Sample size $(n)=130$.

$\dagger, 1 \%$ level of significance.
(Draugalis, Coons \& Plaza 2008). The researchers targeted government officers (26), NGO logistics (35), NGO projects (13) and NGO field officers (100). Out of 174 respondents sampled, a total of 130 of the questionnaires were returned successfully, generating a response of $75 \%$, which was suitable for reliability and validity testing.

Table 3 shows respondents' perceptions of the influence of culture, leadership attitudes, political state, economic state and legal framework on the effectiveness of drought relief supply chains in Zimbabwe. The perceptions were analysed using the non-parametric sign test as suggested by Anderson et al. (2008). The sign test leads to a statistical conclusion in favour of the most supported of the two perceptions (for example, yes or no).

\section{Culture}

Table 3 shows that $79 \%$ of respondents indicated that culture has no positive influence on the effectiveness of drought relief supply chains, against $21 \%$ who suggested that each had a positive effect at a $1 \%$ level of significance. This illustrates that there was no statistical evidence that culture positively influenced the effectiveness of HSCs in Zimbabwe. The lack of a positive impact from a cultural perspective on drought relief in Zimbabwe can be explained by Ringson (2017), Mararike (2001) and Masendeke and Shoko (2014) who agree that the role of traditional leaders in Zimbabwe has diminished over the years. Traditional leaders no longer have the influence they used to have in the community as in past decades (Ringson 2017). A total of 97 respondents strongly disagreed with the hypothesis that culture is an enabler to drought relief supply chains. A total of 10 respondents disagreed with the hypothesis that culture is an enabler, while only 22 respondents agreed that culture is an enabler. The results suggest that culture does not have any positive impact on the effectiveness of drought relief supply chains in Zimbabwe. A total of 107 of the respondents, based on their educational background, affirmed that culture is not viewed as an enabler across all educational categories. This therefore means that traditional leaders have no influence over drought supply chains in Zimbabwe. This finding implies that the progression in intensity of drought disasters in the country requires more than cultural and traditional measures to minimise the impacts of drought disasters on communities.

\section{Leadership attitudes}

Table 3 shows that $79 \%$ of respondents indicated that leadership attitudes have no positive influence on the effectiveness of drought relief supply chains, against $21 \%$ who suggested that each had a positive effect at a $1 \%$ level of significance. The involvement of diverse leaders caused coordination problems, as observed by Balcik et al. (2010). Rey (2001) believes that there have been very few coordination success stories in HSCs and that coordination remains the weakest link. The discord amongst community leaders resulted in an adverse effect on the effectiveness of drought 
supply chains. The research findings further illustrated that $70 \%$ of respondents strongly disagreed with the hypothesis that leadership attitudes enable an effective response to drought relief. The research findings show that 107 respondents (82\% of all educational categories) strongly disagreed with the assertion that leadership attitudes influence drought relief response in a positive way. This finding is in line with the results of a study by Chigwedere et al. (2008). The research finding also implies that educational background influenced the perception of respondents. To further explain this phenomenon, the involvement of diverse leaders causes coordination problems.

\section{Political state}

Table 3 reveals that $80 \%$ of the respondents did not view the political state as an enabler of drought relief supply chains, against $20 \%$ of the respondents. This suggests that the political state of the country does not positively influence the effectiveness of drought supply chains in Zimbabwe at the $1 \%$ level of significance. Table 3 also shows evidence that politics does not positively influence the response to drought relief. This is consistent with the findings of the Zimbabwe Human Rights Commission in 2016 - there was a partisan distribution of food relief. In 2016, the commission even implored politicians not to use food aid to further their political aspirations at the expense of communities. It is important to note that even though politics is not an enabler, it is nonetheless very active in HSCs. This result was consistent with Tomasini and Van Wassenhove (2009), who concluded that HSCs operate in highly politicised environments and that it is impossible to separate HSCs from politics. McEntire (2001) notes that deteriorating political structures create vulnerability for communities' abilities to cope with the impact of disasters. In addition, the International Federation of the Red Cross, as cited by Tomasini and Van Wassenhove (2009), reported that human suffering around the world was largely ignored as political considerations prevailed over humanitarian ones. The ideal situation in humanitarian SCM is for humanitarian mission objectives to take precedence over political considerations.

The research findings illustrate that 108 respondents strongly disagreed with the view that the political state is an enabler of drought relief supply chains in Zimbabwe. Only 10 respondents agreed that the political state is an enabler of drought relief supply chains. This finding implies that the state of politics in the country does not enhance the effectiveness of drought relief supply chains. This finding is in line with the findings of Tomasini and Van Wassenhove (2009:10). Indeed, the political situation of the country is far from perfect. Sanctions imposed on the country by developed economies have had a knockdown effect on the economy.

The research study reveals that 20 respondents with degrees and 63 with diplomas disagreed with the view that the political state is an enabler in drought relief supply chains. It is important to note that even though politics is not an enabler, it is very active in HSCs (McEntire 2001:192).
Tomasini and Van Wassenhove (2009:10) concluded that HSCs operate in highly politicised environments and that it is impossible to separate them from politics.

\section{Economic state}

Table 3 shows that $100 \%$ of the respondents perceived the economic state as having a positive influence on drought relief response in Zimbabwe. The statistical conclusion of the sign test is that the economic state and legal framework have a positive influence on the effectiveness of humanitarian relief response in Zimbabwe at a 1\% level of significance. Table 3 also shows evidence that the economic state positively influenced humanitarian relief supply chains in Zimbabwe. This finding is an interesting one, given that the economy is not in a good state. There is a high level of unemployment, which currently stands at $80 \%$ in the formal sectors of the economy, according to the Zimbabwe National Statistics Agency (ZIMSTAT 2017).

This study illustrates that 129 respondents agreed with the assertion that the economic state is an enabler of the humanitarian relief response. Only one respondent was unsure, and none of the respondents were against the claim that the economic state influenced the effectiveness of drought relief supply chains in Zimbabwe. The implication of this finding is that the economic state influenced the effectiveness of drought relief supply chains in the country. The primary assumption of McEntire (2001:192) is that a well-performing economy is a source of resilience against disasters for individuals and communities. The Zimbabwe National Statistics Agency (2016) also reports that over 60\% of the population is employed in the informal sector. The balance of trade between Zimbabwe and its major trading partner, South Africa, is negative, adding to the woes of the country. According to ZIMSTAT (2017), the informal sector in Zimbabwe is worth over US\$1.7 billion.

\section{Legal framework}

Table 3 shows that $100 \%$ of the respondents perceived the legal framework as having a positive influence on drought relief response in Zimbabwe. Table 3 further reveals that the legal framework was viewed as a positive enabler for drought relief supply chains. The legal framework is a critical mitigating measure which deals with the physical vulnerabilities of communities (McEntire 2001). This finding confirms Henstra and McBean's (2005) conclusion that the Australian Government managed to avert risk through laws that regulated the construction of buildings near dams, and the mandatory purchase of buildings constructed in floodprone areas.

The study shows the perceptions of interviewed respondents as follows: $81 \%$ viewed the disaster policy as an impediment, $92 \%$ viewed leadership attitudes as an impediment, 69\% viewed culture as an impediment and $86 \%$ viewed the political state as an impediment. However, only $26 \%$ of respondents viewed the legal framework as an impediment, 
while $20 \%$ viewed the economic state as an impediment. The findings imply that disaster policy, leadership attitudes, culture and the political state impede the effectiveness of drought relief supply chains in Zimbabwe. The study reveals that the economic state and legal framework were viewed as enablers of an effective drought relief supply chain.

McEntire (2001:191) identified social, physical, cultural, political, economic and technological factors as major factors that increase the vulnerability of communities. What is very clear is that, if the factors identified by McEntire are not improved, they will increase the vulnerability of communities. However, the underlying assumption of McEntire's work is that resilience to the effects of disaster can be achieved by addressing weaknesses in social, physical, cultural, political, economic and technological factors.

The International Federation of the Red Cross, as cited by Tomasini and Van Wassenhove (2009:35), reported that worldwide human suffering was generally ignored because political considerations were more of a priority than humanitarian ones. Tomasini and Van Wassenhove (2009) concede that it is very difficult to isolate humanitarian relief operations from politics. The ideal situation for SCM from a philanthropic point of view is for humanitarian mission objectives to take precedence over political considerations.

The findings indicate that 129 respondents agree with the view that legal framework is an enabler in drought relief response. This finding implies that the legal framework had an influence on drought relief supply chains in Zimbabwe. The legal framework is a critical mitigating measure which deals with the physical vulnerabilities of communities (McEntire 2001:191).

The study findings reveal that 106 respondents strongly disagree with the claim that the drought disaster policy is an enabler of drought relief response. This finding suggests that disaster policy does not influence the effectiveness of drought relief. It confirms the concerns raised by Von Meding (2012:920) in the aftermath of the Hurricane Katrina disaster in New Orleans and how this city can develop although it is situated in a vulnerable location. This situation can be explained by the fact that the current drought management strategies are aimed at increasing agricultural output rather than strategies to respond to the needs of people already in need of food aid (Tadesse 2016:19).

\section{Ordinary least squares estimation of enablers of the drought supply chain}

Tables 4-7 show the OLS estimation of the relationships between the enablers and HSC efficiency, which is specified in Equation 1 in the research methodology section of this study. As Equation 1 specifies, enablers were measured using culture, leadership attitudes, political state, economic state and legal framework. At the same time, supply chain efficiency was proxied by transport costs, warehouse costs, quantities delivered and number of people affected. Equation 1 also includes a vector of the background characteristics of the respondents as well as those of their organisation.

\section{The impact of enablers on transport costs}

Table 4 shows that, save for the legal framework, all enablers do not have a statistically significant impact on transport costs. Column V of Table 4 reveals the OLS results that the legal framework variable resulted in the reduction of transportation costs by $\$ 0.147$ per kilometre. This finding is statistically valid at a $5 \%$ level of significance. The reduction of transport costs can be attributed to government interventions through relevant statutory instruments that promote the smooth movement of relief supplies to affected communities. Goods brought into the country by registered charity organisations are exempted from paying duty and value-added tax in terms of the Customs and Excise Regulations section 124 and Statutory Instrument 154 of 2001. Transport costs form a major part of the expenditure of drought relief (Da Costa et al. 2012; Tomasini \& Van Wassenhove 2009); therefore, the exemption from paying duty, value-added tax, toll fees and other regulatory fees results in a remarkable cost reduction. However, for an organisation or individuals to enjoy these tax benefits, they must be registered in terms of the Private Voluntary Organisations Act [Chapter 17:05].

TABLE 4: The impact of enablers on transport cost.

\begin{tabular}{|c|c|c|c|c|c|}
\hline Enablers & Transport cost (I) & Transport cost (II) & Transport cost (III) & Transport cost (IV) & Transport cost (V) \\
\hline Education & $-0.0371(0.126)$ & $-0.0414(0.122)$ & $-0.0490(0.128)$ & $-0.0324(0.131)$ & $0.00415(0.111)$ \\
\hline Work experience & $0.0306(0.0331)$ & $0.0302(0.0315)$ & $0.0298(0.0321)$ & $0.0294(0.0307)$ & $0.0250(0.0285)$ \\
\hline Government & $-0.996 * * *(0.101)$ & $-1.101 * * *(0.136)$ & $-1.196 * * *(0.134)$ & $-1.116 * * *(0.100)$ & $-1.102 * * *(0.100)$ \\
\hline Culture & $-0.0353(0.0335)$ & - & - & - & - \\
\hline Leadership attitudes & - & $-0.00554(0.0312)$ & - & - & - \\
\hline Political state of the country & - & - & $0.0221(0.0445)$ & - & - \\
\hline Economic state of the country & - & - & - & $-0.0399(0.0693)$ & - \\
\hline Legal framework & - & - & - & - & $-0.147 * *(0.0608)$ \\
\hline Constant & $3.503 * * *(0.374)$ & $3.476 * * *(0.326)$ & $3.437 * * *(0.351)$ & $3.636 * * *(0.570)$ & $4.039 * * *(0.448)$ \\
\hline Observations & 130 & 130 & 130 & 130 & 130 \\
\hline$R$-squared & 0.657 & 0.657 & 0.657 & 0.658 & 0.676 \\
\hline
\end{tabular}

Note: Robust standard errors in parentheses.

$*, p<0.1 ; * *, p<0.05 ; * * *, p<0.01$. 
Column III of Table 5 indicates that the perception of the political state resulted in an increase in warehouse costs by $\$ 213.60$. This finding is statistically significant at the 5\% level.

However, Table 5 reveals no statistical evidence that culture, leadership attitudes, economic state and legal framework have an effect on warehouse costs. The vector for the background characteristics of the respondents has an effect on warehouse costs, as can be seen in column III of Table 5. This table shows that work experience reduced warehouse costs by between $\$ 35.82$ and $\$ 40.53$ per month, depending on the respondent's years of experience. The greater the respondent's experience, the higher their savings on warehouse costs. This result was statistically significant at the $10 \%$ level. Table 5 also reveals that the level of education resulted in the reduction of warehouse costs by $\$ 286.20$ per month. This finding is significant at the $10 \%$ level.

Work experience and education are crucial in empowering role players to plan for relief logistics operations. The importance of planning in humanitarian logistics was emphasised by Balcik et al. (2010), Oloruntoba and Gray (2006) and Tomasini and Van Wassenhove (2009). The finding on the relationship between work experience and warehouse costs can be explained by the learning curve theory because experience and education enhance the ability to learn quickly. The major assumption of the learning curve is that proficiency increases with experience (Wright 1936). This finding confirms that work experience and the level of education helped the respondents to reduce warehousing costs through the accurate forecasting of demand, and a reduction in damages and waste. Furthermore, good relationship management with the warehouse proprietors was found to result in no additional charges for storage beyond agreed tenure periods, and an appreciation of cheaper security options.

Table 6 illustrates that there is no statistical evidence showing any relationship between culture, leadership attitudes, economic state, political state and legal framework on the quantity delivered, as indicated by coefficients $-21.90,9.90,-22.60,48.00$ and -66.02 , respectively. This is evidenced by the standard errors for each variable, which are too large at 22.93 for culture, 32.93 for leadership attitudes, 35.9 for political state, 33.99 for economic state and 42.92 for legal framework. The vector for background characteristics shows that the type of organisation has an impact on the quantity delivered for drought relief. Table 6 also reveals that the government delivered about 230221 tonnes of relief aid per month. This finding is valid at a $1 \%$ level of significance.

According to Table 6, the OLS procedure did not reveal any statistical relationships between all of the enablers and the quantities delivered to communities. However, the vector

TABLE 5: The impact of drought relief enablers on warehouse costs.

\begin{tabular}{|c|c|c|c|c|c|}
\hline Variables & Warehouse costs (I) & Warehouse costs (II) & Warehouse costs (III) & Warehouse costs (IV) & Warehouse costs (V) \\
\hline Education & $-224.6(137.6)$ & $-244.8(139.8)$ & $-286.2 *(137.2)$ & $-222.2(131.3)$ & $-183.1(118.8)$ \\
\hline Work experience & $-35.82 *(16.22)$ & $-39.61 * *(16.22)$ & $-38.17 *(18.06)$ & $-36.15 *(16.80)$ & $-40.53 * *(16.02)$ \\
\hline Culture & $-7.742(57.29)$ & - & - & - & - \\
\hline Leadership attitudes & - & $81.33(81.26)$ & - & - & - \\
\hline Political state of the country & - & - & $213.6 * *(77.39)$ & - & - \\
\hline Legal framework & - & - & - & & $-133.9(89.79)$ \\
\hline Constant & $1.406 * * *(216.9)$ & $1.280 * * *(263.6)$ & $1.106 * * *(241.7)$ & $1.459 * * *(448.7)$ & $1.920 * * *(466.4)$ \\
\hline Observations & 130 & 130 & 130 & 130 & 130 \\
\hline$R$-squared & 0.048 & 0.055 & 0.087 & 0.049 & 0.073 \\
\hline
\end{tabular}

Note: Robust standard errors in parentheses.

$*, p<0.1 ; * *, p<0.05 ; * * *, p<0.01$.

TABLE 6: The impact of enablers on quantity delivered.

\begin{tabular}{|c|c|c|c|c|c|}
\hline Enablers & Quantity delivered & Quantity delivered & Quantity delivered & Quantity delivered & Quantity delivered \\
\hline Education & $-81.59(66.72)$ & $-87.41(64.76)$ & $-98.65(67.75)$ & $-79.24(73.14)$ & $-64.01(66.55)$ \\
\hline Work experience & $-6.817(14.28)$ & $-7.644(13.13)$ & $-7.693(13.46)$ & $-7.502(13.33)$ & $-9.453(11.98)$ \\
\hline Government & $230641 * * *(89.39)$ & $23154 * * *(101.1)$ & $230221 * * *(106.9)$ & $231893 * * *(64.76)$ & $231952 * * *(65.69)$ \\
\hline Culture & $-21.94(22.93)$ & - & - & - & - \\
\hline Leadership attitudes & - & 9.947 (32.93) & - & - & - \\
\hline Political state of the country & - & - & $47.99(35.92)$ & - & - \\
\hline Economic state of the country & - & - & - & $-22.62(33.99)$ & - \\
\hline Legal framework & - & - & - & - & $-66.02(42.92)$ \\
\hline Constant & $794.1 * * *(176.3)$ & $757.7 * * *(173.1)$ & $706.5^{* * *}(170.3)$ & $867.6 * * *(231.8)$ & $1029 * * *(275.7)$ \\
\hline Observations & 130 & 130 & 130 & 130 & 130 \\
\hline$R$-squared & 1.000 & 1.000 & 1.000 & 1.000 & 1.000 \\
\hline
\end{tabular}

Note: Robust standard errors in parentheses.

$*, p<0.1 ; * *, p<0.05 ; * * *, p<0.01$. 
for background characteristics reveals that government drought supply chains moved 200000 tonnes of relief aid in 2016. This finding can be explained by the fact that the government distributes much food aid across the country. The government is responsible for distributing food aid to all drought-prone areas in the country, and NGOs are responsible for specific relief areas as mandated by the WFP, which results in moving lower quantities each month. The government is also responsible for the welfare of elderly people, orphans and the destitute residing in urban areas. The drought relief action of the government, which covers extensive areas affected by drought, is in line with the humanitarian concept. Tomasini and Van Wassenhove (2009) define humanitarian action as the observance of humanity, neutrality and impartiality when carrying out humanitarian operations. Neutrality, kindness and fairness are important humanitarian principles that should form the basis of a country's disaster management policy. The increasing number of deliveries is also consistent with the report by ZIMVAC: that over two million people needed food aid in 2016.

Table 7 shows that there is no statistical evidence of any relationship between culture, leadership attitudes, political state, economic state and legal framework and the number of people affected, as evidenced by the regression coefficients $-1.800,828.900,3.999,-1.885$ and -5.500 , respectively. The reported standard errors are too wide; therefore, the sample size was not able to accurately reveal any meaningful relationships between the enablers and the number of people affected by drought relief supply chains. According to Walliman (2011), as the sample increases the standard error will decrease. This suggests that the mean increases, depending on the sample size. The vector for background characteristics reveals an increasing number of people being affected by government initiatives of relief supply chains. This finding is statistically valid at a $1 \%$ level of significance.

Table 7 also indicates that the OLS procedure revealed that statistically there is no relationship between enablers and the number affected by drought relief supply chains in Zimbabwe. However, the vector for background characteristics shows that the government relief supply chains have affected a significant number of people in need of food assistance. The 2015 and 2016 agricultural season was declared a national disaster. The onset of the El-Nino effect resulted in the widespread reduction of rainfall in most parts of Zimbabwe. This has seen over three million people affected and consequently in dire need of food assistance (ReliefWeb 2016).

\section{Conclusion}

The primary focus of this study was determining the influences of culture, leadership attitudes, political state, economic state and legal framework on HSC effectiveness in drought relief operations in Zimbabwe. The study identifies country-specific factors such as economic state and legal framework as having an impact on drought relief operations. Culture, leadership attitudes and political state were found in this study to not have a positive influence on drought relief supply chains in Zimbabwe. Culture and leadership attitudes rely heavily on the diminishing role of traditional leaders, as the government has taken over social activities to protect vulnerable groups in society. This study observed that the political state of the country did not support an effective drought response in Zimbabwe. Questionable political processes resulted in increased costs of operations for drought response and caused delays in the distribution of food aid to beneficiaries.

The legal framework positively influenced drought relief supply chains in Zimbabwe as the government passes pieces of legislation that facilitate the movement of drought relief supplies; for example, the exemption of duty and tax payments on goods imported for humanitarian aid purposes. The Private Voluntary Organisation Act and the Civil Protection Act resulted in the reduction of transport and warehousing costs.

The Zimbabwean Government should review a disaster risk management strategy to combat the negative influences of culture, leadership attitudes and political interference in providing humanitarian relief. Furthermore, there is a need to establish provincial task forces comprised of critical stakeholders to oversee responses to drought relief and to ensure effectiveness. Treasury should create a drought

TABLE 7: The impact of enablers on number affected.

\begin{tabular}{|c|c|c|c|c|c|}
\hline Enablers & Number affected & Number affected & Number affected & Number affected & Number affected \\
\hline Education & $-6799(5560)$ & $-7284(5396)$ & $-8221(5646)$ & $-6603(6095)$ & $-5334(5546)$ \\
\hline Work experience & $-568.1(1190)$ & $-637.0(1094)$ & $-641.1(1122)$ & $-625.1(1110)$ & $-787.7(998.7)$ \\
\hline Government & $1.939 \mathrm{e}+06 * * *(7449)$ & $1.930 \mathrm{e}+06 * * *(8425)$ & $1.918 \mathrm{e}+06 * * *(8908)$ & $1.932 \mathrm{e}+06 * * *(5397)$ & $1.933 \mathrm{e}+06 * * *(5474)$ \\
\hline Culture & $-1828(1911)$ & - & - & - & - \\
\hline Leadership attitudes & - & $828.9(2744)$ & & & \\
\hline Political state of the country & - & - & $3999(2993)$ & - & - \\
\hline Legal framework & - & - & - & - & $-5501(3577)$ \\
\hline Constant & $66172 * * *(14695)$ & $63143 * * *(14422)$ & $58876 * * *(14190)$ & $72304 * * *(19316)$ & $85756 * * *(22$ 977) \\
\hline Observations & 130 & 130 & 130 & 130 & 130 \\
\hline$R$-squared & 1.000 & 1.000 & 1.000 & 1.000 & 1.000 \\
\hline
\end{tabular}

Note: Robust standard errors in parentheses.

$*, p<0.1 ; * *, p<0.05 ; * * *, p<0.01$. 
fund to help finance the Department of Civil Protection to coordinate the activities of diverse role players such as NGOs, chiefs and politicians. The agriculture department should train major role players to enhance HSC planning as drought relief operations involve SCM. Lastly, to improve the effectiveness of drought relief supply chains, major role players such as the government and NGOs should share infrastructure such as warehouse facilities and transport.

The limitations of this study were theoretical and methodological as the scholarly literature is limited in this field of study; also, the selection of districts cannot be generalised throughout Zimbabwe due to the sample size of 130 respondents. This necessitates future researchers to target other geographical areas which are most prone to drought, to increase the sample size and to apply other research methods such as focus groups and document analysis.

\section{Acknowledgements Competing interests}

The authors have declared that no competing interests exist

\section{Authors' contributions}

All authors contributed equally to this work.

\section{Ethical consideration}

This article followed all ethical standards for research without direct contact with human or animal subjects.

\section{Funding information}

This research received no specific grant from any funding agency in the public, commercial or not-for-profit sectors.

\section{Data availability statement}

Data can be accessed via a written request to the correspondence author.

\section{Disclaimer}

The views and opinions expressed in this article are those of the authors and do not necessarily reflect the official policy or position of any affiliated agency of the authors.

\section{References}

Agarwal, S. \& Singh, K., 2018, 'Enhancing supply chain of humanitarian SCM: A case study', International Journal of Applied Engineering Research 13(6), 99-110.

Anderson, D.R., Sweeney, D.J., Williams, T.A., Camm, J.D. \& Cochran, J.J., 2008, Statistics for business and economics, vol. 10, Thomson South-Western, Mason, $\mathrm{OH}$.

Anseeuw, W., Alden, W.L., Cotula, L. \& Taylor, M., 2012, Land rights and the rush for land: Findings of the global commercial pressures on land research project International Land Coalition, Rome.

Balcik, B., Beamon, B.M., Krejci, C.C., Muramatsu, K.M. \& Ramirez, M., 2010 'Coordination in humanitarian relief chains: Practices, challenges and opportunities', International Journal of Production Economics 126(1), 22-34. https://doi.org/10.1016/j.ijpe.2009.09.008
Beamon, B.M. \& Balcik, B., 2008, 'Performance measurement in humanitarian relief chains', International Journal of Public Sector Management 21(1), 4-25.

Bongo, P.P., Chipangura, P., Sithole, M. \& Moyo, F., 2013, 'A rights-based analysis of disaster risk reduction framework in Zimbabwe and its implications for policy and practice', Jàmbá: Journal of Disaster Risk Studies 5(2), 1-11. https://doi. org/10.4102/jamba.v5i2.81

Cameron, A.C. \& Trivedi, P.K., 2005. Microeconometrics: Methods and applications. Cambridge University Press.

Carr, L.J., 1932, 'Disaster and the sequence-pattern concept of social change', American Journal of Sociology 38(2), 207-218. https://doi.org/10.1086/216030

Chari, F. \& Ngcamu, B.S., 2017a, 'An assessment of the impact of disaster risks on dairy supply chain performance in Zimbabwe', Cogent Engineering 4(1), 1409389 https://doi.org/10.1080/23311916.2017.1409389

Chari, F. \& Ngcamu, B.S., 2017b, 'The impact of collaborative strategies on disaster risk reduction in Zimbabwe dairy supply chains in 2016', TD: The Journal for Transdisciplinary Research in Southern Africa 13(1), 1-9. https://doi.org/10.4102/ td.v13i1.433

Chari, F. \& Ngcamu, B.S., 2019a, 'The impact of disaster risks on economic sustainability of cotton supply chains: Evidence from Chiredzi District, Zimbabwe', Cogent Socia Sciences 5(1), 1625742

Chari, F. \& Ngcamu, B.S., 2019b, 'A synthesis of risks in dairy value chains in Southern Africa: Cases of South Africa and Zimbabwe', in S. Ibrahim (ed.), Handbook of modern dairy science and technology, IntechOpen, London.

Chatiza, K., 2019, Cyclone Idai in Zimbabwe: An analysis of policy implications for postdisaster institutional development to strengthen disaster risk management, Oxfam, Zimbabwe.

Chigwedere, P., Seage, G.R. III, Gruskin, S., Lee, T-H. \& Essex, M., 2008, 'Estimating the lost benefits of antiretroviral drug use in South Africa', Journal of Acquired Immune Deficiency Syndromes 49(4), 410-415. https://doi.org/10.1097/ QAI.0b013e31818a6cd5

Collier, P., 2008, 'The politics of hunger: How illusion and greed fan the food crisis', Foreign Affairs 87(6), 67-79.

Coppola, D.P., 2011, Introduction to international disaster management, 2 nd edn., Butterworth-Heinemann, Oxford, UK.

Cozzolino, A., 2012, Humanitarian logistics, Springer, Manhattan, New York City.

Da Costa, S.R.A., Campos, V.B.G. \& De Mello Bandeira, R.A., 2012, 'Supply chains in humanitarian operations: Cases and analysis', Procedia: Social and Behavioral Sciences 54, 598-607. https://doi.org/10.1016/j.sbspro.2012.09.777

Devi, S., 2019, 'Cyclone Idai: 1 month later, devastation persists', The Lancet 393(10181), 1585. https://doi.org/10.1016/S0140-6736(19)30892-X

Draugalis, J.R., Coons, S.J. \& Plaza, C.M., 2008, 'Best practices for survey research reports: A synopsis for authors and reviewers', American Journal of Pharmaceutical Education 72(1), 1-6. https://doi.org/10.5688/aj720111

EM-DAT, 2014, viewed 12 May 202, from https://www.emdat.be.

Government of Zimbabwe, Civil Protection Act [Chapter 10:06] of 2001.

Government of Zimbabwe, Private Voluntary Organisations Act [Chapter 17:05] of 2002.

Henderson, D.A., Chase, B.W. \& Woodson, B.M., 2002, 'Performance measures for NPOs', Journal of Accountancy 193(1), 63-68.

Henstra, D. \& McBean, G., 2005, 'Canadian disaster management policy: Moving toward a paradigm shift?', Canadian Public Policy/Analyse de Politiques 31(3), 303-318. https://doi.org/10.2307/3552443

Hosseini, S., Ivanov, D. \& Dolgui, A., 2019, 'Review of quantitative methods for supply chain resilience analysis', Transportation Research Part E: Logistics and Transportation Review 125, 285-307. https://doi.org/10.1016/j.tre.2019.03.001

IFRC, 2003, viewed 12 May 2020, from https://www.ifrc.org/en/news-and-media/ opinions-and-positions/speeches/2003.

Kara, B.Y. \& Rancourt, M.È., 2019, 'Location problems in humanitarian supply chains', in G. Laporte, S. Nickel \& F. Saldanha da Gama (eds.), Location science, pp. 611629 , Springer, Cham, Switzerland.

Khan, S., Mushtaq, S., Hanjra, M.A. \& Schaeffer, J., 2008, 'Estimating potential costs and gains from an aquifer storage and recovery program in Australia', Agricultural Water Management 95(4), 477-488. https://doi.org/10.1016/j.agwat.2007. Water
12.002

Mararike, C.G., 2001, 'Revival of indigenous food security strategies at the village level: The human factor implications', ZAMBEZIA: Journal of Humanities of the University of Zimbabwe, 28(1), 53-66.

Marshall, C. \& Rossman, G.B., 2006, Designing qualitative research, SAGE Publications, viewed 12 May 2020, from https://books.google.co.zw/books?id=Wt3Sn WOJCOC.

Masendeke, S. \& Shoko, K., 2014, 'Drought coping strategies and their effectiveness: The case of Ward 12 in Mberengwa District Zimbabwe', International Journal of Social Science Studies 2(1), 137-152. https://doi.org/10.11114/ijsss.v2i1.299

McEntire, D.A., 2001, 'Triggering agents, vulnerabilities and disaster reduction: Towards a holistic paradigm', Disaster Prevention and Management 10(3), 189-196. https://doi.org/10.1108/09653560110395359

Mhlanga, C., Muzingili, T. \& Mpambela, M., 2019, 'Natural disasters in Zimbabwe: The primer for social work intervention', African Journal of Social Work 9(1), 46-54.

Mohan, S., Gopalakrishnan, M. \& Mizzi, P.J., 2013, 'Improving the efficiency of a nonprofit supply chain for the food insecure', International Journal of Production Economics 143(2), 248-255. 
Muchanyerei, B., 2017, 'Apathy or fear? The role of social workers in Zimbabwe's political discourse', African Journal of Social Work 7(2), 60-64.

Mzumara, M., 2012, 'An overview of Zimbabwe's macroeconomic environment', International Journal of Economic Research 3(1), 33-69.

Nunn, P.D., Hunter-Anderson, R., Carson, M.T., Thomas, F., Ulm, S. \& Rowland, M.J., 2007, 'Times of plenty, times of less: Last-millennium societal disruption in the Pacific Basin', Human Ecology 35(4), 385-401. https://doi.org/10.1007/s10745006-9090-5

Oliver-Smith, A. \& Hoffman, S., 1999, 'Anthropology and the angry earth: An overview', in A. Oliver-Smith and S. Hoffman (eds.), The angry earth, pp. 15-30, Routledge, New York.

Oloruntoba, R. \& Gray, R., 2006, 'Humanitarian aid: An agile supply chain?', Supply Chain Management 11(2), 115-120. https://doi. org/10.1108/13598540610652492

Pateman, H., Hughes, K. \& Cahoon, S., 2013, 'Humanizing humanitarian supply chains: A synthesis of key challenges', The Asian Journal of Shipping and Logistics 29(1), 81-102.

Quinlan, C., Barry, B., Carr, J. \& Griffin, M., 2019, Business research methods, SouthWestern Cengage, Andover, UK.

ReliefWeb, 2016, 'Zimbabwe Vulnerability Assessment Committee (ZimVAC) 2016 rural livelihoods assessment', viewed 12 May 2020, from https://reliefweb.int/ report/zimbabwe/zimbabwe-vulnerability-assessment-committee-zimvac-2016report/zimbabwe/zimbabwe-
rural-livelihoods-assessment.

Reserve Bank of Zimbabwe, 2016, Annual Report, viewed 12 May 2020, from https:// www.rbz.co.zw/index.php/publications-notices/publications/annual-reports/76annual-report.

Rey, F., 2001. 'The complex nature of actors in humanitarian action and the challenge of coordination'. In Reflections on humanitarian action: Principles, ethics and contradictions. TNI/Pluto Press with Humanitarian Studies Unit and ECHO contradictions. TNI/Pluto Press with Humanitarian
(European Commission Humanitarian Office), London.

Ringson, J., 2017, 'Zunde raMambo as a traditional coping mechanism for the care of orphans and vulnerable children: Evidence from Gutu District, Zimbabwe', African Journal of Social Work 7(2), 52-59.

Sekaran, U., 2009, Research methods for business: A skill building approach, 4th edn. John Wiley \& Sons, Inc., New York, NY.
Tadesse, T., 2016, 'Strategic framework for drought management and enhancing resilience in Africa', African Drought Conference 2016, Drought Risk Management and Enhancing Resilience in Africa, Windhoek, Namibia.

Tomasini, R. \& Van Wassenhove, L., 2009, Humanitarian logistics, Palgrave Macmillan, London.

Van Wassenhove, L.N., 2006, 'Blackett memorial lecture. Humanitarian aid logistics: Supply chain management in higher gear', Journal of the Operational Research Society 57(5), 475-489. https://doi.org/10.1057/palgrave.jors.2602125

Von Meding, J.K., 2012, 'Emergency management in developed countries: An investigation of hazard risk, vulnerability and government response in the UK and USA', Disaster Advances 5(4), 921-927.

Walliman, N., 2011, Research methods: The basics, Routledge, London.

Wisner, B., Blaikie, P., Cannon, T. \& Davis, I., 2004, At risk: Natural hazards, people's vulnerability and disasters, 2 nd edn., Routledge, London.

Wooldridge, J.M., 2002, Econometric analysis of cross section and panel data, MIT Press, viewed 12 May 2020, from https://books.google.co.zw/books?id=cdBPOJUP4VsC.

World Food Programme, 2016, WFP Southern Africa El Nino Situation Report, viewed 12 May 2020, from https://documents.wfp.org/stellent/groups/public/ documents/ep/wfp281523.pdf.

Wright, T.P., 1936, 'Factors affecting the cost of airplanes', Journal of Aeronautical Sciences 3(4), 122-128. https://doi.org/10.2514/8.155

Xu, S., Zhang, X., Feng, L. \& Yang, W., 2020, 'Disruption risks in supply chain management: A literature review based on bibliometric analysis', International Journal of Production Research, 1(2), 1-19. https://doi.org/10.1080/00207543.2020.1717011

ZHRC, 2016, viewed 12 May 2020, from http://www.zhrc.org.zw/download/2016annual-report/

Zimbabwe Human Rights Commission, 2016, viewed 12 May 2020, from http://www. zhrc.org.zw/download/2016-annual-report.

Zimbabwe National Statistics Agency, 2016, viewed 12 May 2020, from http://www. zimstat.co.zw

Zimbabwe Statistical Office, 2017, viewed 12 May 2020, from http://www.zimstat.co.zw.

ZIMSTAT, 2017, 'Zimbabwe country analysis working document final draft', viewed 12 May 2020, from http://www.zimstat.co.zw. 